\title{
REFORMISMO, DIFUSIÓN Y LEGADO MUSICAL DE FRANCISCO GINER DE LOS RÍOS
}

\author{
FERRAN RIESGO MARTÍNEZ \\ Universidad de Alicante
}

\section{Resumen}

Francisco Giner de los Ríos creció y se formó en una España en que la música culta, ya perdida la ilusión de consolidar una ópera nacional propia, braceaba desordenadamente para no hundirse del todo, y la enseñanza musical reglada daba sus primeros y torpes pasos. En esta coyuntura, entre finales del siglo XIX y principios del XX, Giner comenzó a trabajar en varios frentes para cambiar las formas de enseñar música, siempre apoyándose en el ideario krausista. Este artículo propone un panorama de la tarea gineriana e institucionista en este campo, dividida en tres grandes cursos de acción: el impulso reformista en las enseñanzas profesionales de música, la importancia concedida a lo musical en la ILE, y la labor que la Residencia de Estudiantes o las Misiones Pedagógicas continuaron desempeñando tras la muerte del maestro.

Palabras clave: Giner de los Ríos; Eduardo Martínez Torner; Institución Libre de Enseñanza; Misiones Pedagógicas; Residencia de Estudiantes; música; educación; enseñanza.

\begin{abstract}
In the Spain where Francisco Giner de los Ríos was born and educated, classical music was desperately struggling not to sink completely. The hope for a consolidated national opera was definitely lost, and formal musical education was timidly starting to develop. Thus, in the late $19^{\text {th }}$ century, Giner, always loyal to Krause's aesthetics and social beliefs, started to work in order to change the way music was being taught. This article offers an outlook on the Institución Libre de Enseñanza and Giner's efforts on this field, divided in three main courses of action: the reform on professional music education, the importance of music within the ILE, and the way institutions like the «Misiones Pedagógicas» or the «Residencia de Estudiantes» continued Giner's work after his death.
\end{abstract}

Keywords: Giner de los Ríos; Eduardo Martínez Torner; Institución Libre de Enseñanza; Misiones Pedagógicas; music; teaching; education.

Anales, 27 (2015), pp. 107-129

DOI: 10.14198/ALEUA.2015.27.06 


\section{Obertura}

Cuarenta canciones españolas (Madrid, Residencia de Estudiantes, 1924) no es la obra más conocida del musicólogo asturiano Eduardo Martínez Torner, pero sin duda es la que está más estrechamente relacionada con los esfuerzos que Francisco Giner de los Ríos y otros intelectuales afines hicieron en favor de la música. En el prefacio de este libro escribe Torner:

Es innegable el valor de la música como medio para la formación del espíritu. Pero si, en realidad, las obras de los grandes maestros solo pueden ser gustadas actualmente por una minoría selecta, la canción popular, en cambio, encuentra en el espíritu de todos suficientes puntos de referencia para que sea escuchada con emoción, y ofrece, además, abundantes ejemplos de buen arte para que el sentido musical se desarrolle de modo adecuado hasta elevarse a aquel grado de sensibilidad que hace posible ulteriormente la comprensión de las obras geniales (Torner, 1924: XIV).

Son las palabras de alguien que habla de emprender una larga tarea, la de sentar las bases de una cultura y un gusto musicales elevados para todos los estratos sociales. Y, sin embargo, Torner recorrió solamente las últimas etapas - trabajó intensamente en la Residencia de Estudiantes y las Misiones Pedagógicas - de un camino que Giner había comenzado a andar mucho antes, al mismo tiempo que sentaba las bases de la futura ILE. Este, por su parte, escribía en el prólogo de Estudios de literatura y arte: "el nuevo [arte] ideal se halla en germinación, y tan segura como ha de ser en todas las esferas su victoria, tan imposible es lograrla en nuestros días» (Giner, 1876: XII); pero se trataba, con todo, de un alegato optimista: «prepararemos el suelo para que el germen eternamente sembrado arraigue, y prospere, y llegue en su día a florecer y dar fruto» (ibid.). El contenido es similar al del texto de Torner, pero, a pesar de las décadas que median entre ambos, la semejanza de los mensajes no revela una tarea infructuosa, sino, al contrario, la perseverancia y la coherencia de un proyecto reformista que se mantuvo hasta el fin mismo de la II República.

Giner y sus colaboradores no fueron los primeros en diagnosticar los males de la música española en el XIX, pero sí fueron el núcleo generador de un verdadero cambio en el panorama de la pedagogía musical. Los puntos más criticados por los intelectuales de la época eran el excesivo gusto por lo extranjero - lo italiano, sobre todo-, la baja cultura musical del público, el poco o nulo amparo prestado por los gobiernos, el mal estado de los teatros, la precariedad de los intérpretes y, en definitiva, la falta de una verdadera tradición musical viva. Son todas facetas de una 
misma realidad: pasados los esplendores del Renacimiento y el Barroco, en España el interés y el apoyo a la música se habían ido desplomando década tras década, y a finales del Ochocientos los intelectuales miraban hacia Europa con franca añoranza y amargura.

Don Francisco no era una excepción, y en sus escritos sobre educación se referiría ocasionalmente a las prácticas de otras naciones en materia de música ${ }^{1}$. El pedagogo era lo que por entonces llamaban «un filarmónico»: un amante de la música, que frecuentaba conciertos y reuniones privadas, se defendía bien al piano, y, desde su llegada a Madrid en 1863, fue un habitual de la Sociedad Filarmónica y la Sociedad de Cuartetos. Ello aportaba un trazo distintivo a su perfil de ilustrado y esteta, e indudablemente parte de su interés por la pedagogía musical nacía de la inclinación personal, de la propia experiencia artística. Sin embargo, las raíces más recias de su empeño reformador debemos buscarlas en el sustrato común de la doctrina krausista, que concedía una importancia capital a la faceta artística de la vida humana. Giner, que en Estudios de literatura y arte definía, siguiendo a Krause, la música como «el bello arte que expresa la belleza interior de la vida del ánimo en el mundo de los sonidos» (1876: 89), concretaba en la música esta capacidad especial del arte para influir en el espíritu de las personas:

Y pues que el sonido es esencial manifestación de la vida toda del sentimiento, así de la del cuerpo como de la del espíritu, pudiendo esta vida ser informada poéticamente mediante la libertad del espíritu y por ministerio de la fantasía en la bella vitalidad de los tonos; y pues la vida del ánimo humano se corresponde y concuerda con aquella de la Naturaleza, asemejándose por esto, en sus límites, a la divina, debe considerarse a la Música, en cuanto comprende la expresión de la vida entera de todos los seres, como un arte verdaderamente humano-divino (ibid.).

Conservamos las mayúsculas de Giner. Detrás de esta visión de la música está la triada platónica de belleza, verdad y bien, asumida a su modo por Krause y sus seguidores, que aparece aquí relacionada con ese equilibrio orgánico entre el hombre y lo divino, entre el hombre y la Naturaleza. Por consiguiente, la música debía jugar un papel central en la educación del individuo, en tanto que una de las bellas artes (y la de influjo más intenso

1. Vid. especialmente Obras completas, XVI: Ensayos menores sobre educación y enseñanza ( La enseñanza superior y técnica en Francia», 276 ss.). De ahora en adelante, las fuentes de textos de Giner se indicarán así: las iniciales OC (Obras completas) y, tras coma, el número de volumen de la edición de Espasa-Calpe, salvo en el caso de Estudios sobre literatura y artes (1876); aquí: OC, XVI: 276 ss. 
y sutil), y Giner mostraba en el «Prólogo» una preocupación sincera por el estado general del arte del momento. Una belleza «privada de toda su propia y sustantiva finalidad, como de toda virtud ética, y con esto de su dignidad y elevado sentido» (1876: XIV), no podía sino dañar la conciencia de los jóvenes: «de esta suerte, torcida la natural tendencia con que gravita hacia lo bello el espíritu, se pervierte y corrompe, por falta de dirección adecuada» (ibid.). Se entiende así que el objetivo central fuera lograr una influencia sólida, duradera y general en la sociedad española a través del arte. La circulación del arte bello, puro, que los krausistas distinguían del «arte útil» (vid. el mismo «Prólogo» a Estudios...), debía producirse de forma piramidal: unos pocos profesionales —músicos y compositoresdebían estar excelentemente formados para poder transmitir un objeto artístico puro a un público que había de estar educado en su recepción y aprecio; si era posible desde la infancia, tanto mejor, pues el propio influjo de la música y otras artes contribuiría a su crecimiento en esa «dirección adecuada» a la que se refería el maestro.

Para sostener esta estructura de comunicación Giner siguió tres cauces de acción principales, bien diferenciados: por un lado, la educación musical superior, es decir la formación de músicos profesionales; por otro, la presencia de la música en la educación primaria y secundaria, y más concretamente en los cursos de la ILE; finalmente - aprovechando las infraestructuras primero de la ILE, luego del Ateneo y más adelante de la Residencia y las Misiones-, la difusión musical pública, más allá del sistema educativo reglado. Naturalmente, desde dentro y fuera de la Institución contó con la ayuda de muchas otras gentes de cultura que, casi siempre de forma desinteresada, pusieron sus conocimientos sobre música al servicio de una tarea ambiciosa y muy exigente. De todas ellas, probablemente fue Eduardo Martínez Torner quien más contribuyó a la causa tras la muerte de Giner.

\section{Sobre el Real Conservatorio y la Academia de Santa Cecilia}

Podemos tomar un lugar y una fecha, Cádiz y el 1 de abril de 1875, como puntos de partida para la cruzada de Giner por una enseñanza musical profesional de calidad. Había llegado la madrugada del día 1 a la ciudad, destituido de su cátedra en la Universidad Nacional y desterrado tras el conocido como «Decreto Orovio» ${ }^{2}$. Allí recibió la visita de los krausistas

2. Manuel Orovio Echagüe, marqués de Orovio y Ministro de Fomento de Alfonso XII en 1875 elevó al rey una petición que consistía, esencialmente, en eliminar la libertad 
Alfonso Moreno Espinosa y Romualdo Álvarez Espino, y pronto comenzó a participar intensamente en la vida cultural gaditana. En una carta a Gumersindo de Azcárate hablaba de una «gran sesión musical» que se celebraba los martes y los domingos en casa de un comerciante: «suele agregarse el director del Instituto, hombre joven, culto, sumamente listo. Tocamos, por supuesto, Mozart, Haydn, Beethoven, Wagner. Tenemos quinteto de cuerda, dos pianos y armónium» (en Sopeña, 1990: 133); la cursiva es suya.

Una vez introducido en el ambiente, ese mismo año entró en contacto con los docentes de la Academia de Santa Cecilia, una floreciente escuela profesional de música donde buena parte de los enseñantes eran krausistas o simpatizantes del movimiento. Fundada en 1859, Antonio Martín la considera «una de las instituciones musicales más importantes del siglo XIX en España», y recoge una cita de su Memoria en que se afirma que, en el año 59, "ya no existía... sociedad ni establecimiento alguno donde se practicara públicamente la enseñanza de la música» (Martín Moreno, 2005: 86-87), salvo la propia Santa Cecilia, claro. El centro, pues, contaba casi veinte años de historia cuando Giner entró en su círculo, y era ya un enclave famoso de la vida musical de Cádiz.

Por lo que Giner conocía del Real Conservatorio de Madrid y otras escuelas, su deseo era principalmente ampliar la formación teórica, estética e histórica de los futuros intérpretes, cuyos estudios estaban basados en un enfoque excesivamente técnico de la música: a su juicio, el Conservatorio estaba formando solo instrumentistas, no músicos completos, y este era un grave error que debía subsanarse. Más tarde haría públicas sus críticas al centro madrileño, pero empleó su temporada en Cádiz en comprender cómo se trabajaba en Santa Cecilia y, por más que de entrada se hubiera admirado de su autonomía y calidad, también en revisar y reformar sus enseñanzas. A modo de consejero externo, colaboró en la

de cátedra en todos los niveles de la educación. Publicado como Real Decreto el 26 de febrero, y conocido como «Decreto Orovio», algunos de sus artículos establecían que «los Catedráticos de segunda enseñanza y los de la superior y profesional» debían remitir al Gobierno, «por conducto de los Rectores los programas que hayan formado o adoptado para sus respectivas asignaturas» (art. 4), o que sería el Consejo de Instrucción Pública el que se ocuparía de «los programas generales de estudios para el curso próximo, extensivos a todos los grados y órdenes de la pública enseñanza» (art. 5). Giner, que se negó a acatarlo, fue expulsado de su cátedra, desterrado a Cádiz y recluido la madrugada del 1 de abril en el castillo de Santa Catalina, aunque permaneció poco tiempo allí; gravemente enfermo de anginas, el día 15 fue trasladado al hospital, donde comenzó a mejorar. 
ampliación y mejora del programa de estudios, y animó a algunos de los maestros del centro a escribir manuales para las nuevas asignaturas. Hay cartas y registros de las actas de la Academia en los que consta el agradecimiento del claustro y la dirección por los consejos recibidos (Sánchez de Andrés, 2009: 230 ss.).

En algunos casos los manuales escritos fueron los primeros textos españoles específicos sobre la materia: allí habían enseñado o enseñaban Salvador Arpa y López (autor del Manual de Estética y Teoría del arte escrito para la enseñanza de las alumnas y alumnos del Instituto Musical de Santa Cecilia de Cádiz, de 1876), Romualdo Álvarez Espino (autor del Sumario de Historia de la Música moderna para uso de las alumnas del Real Instituto Filarmónico de Santa Cecilia, de 1883) o José Alcolea (Elementos de Acústica y Teoría física de la Música, del mismo año). Don Francisco estaba especialmente orgulloso del manual de acústica, una disciplina aún joven en el país, y que él consideraba indispensable para un conocimiento completo del hecho musical; para un esteta krausista habría sido erróneo desatender la vertiente más científica de una de las bellas artes, especialmente de una tan vinculada a la física y las matemáticas desde la Antigüedad.

En Santa Cecilia Giner encontró un clima idóneo para comenzar su labor y fortalecer sus convicciones pedagógicas. Cierto es que también tuvo que enfrentarse a la oposición de algunos padres de alumnos, y a la indiferencia o el desdén de varios estudiantes y profesores (Sánchez de Andrés, 2009: 239), pero no fue la tendencia dominante. Queda claro, en cualquier caso, que para el desarrollo de una disciplina musical sólida, tan importantes eran la cultura y las opiniones sobre música de Giner como el disponer de un círculo de eruditos que las sostuvieran y pusieran, a veces, las primeras piedras de saberes todavía lejos de afianzarse en España ${ }^{3}$.

Mientras tanto, en Madrid funcionaba regularmente el único conservatorio de la nación. Como tal, el conservatorio era una institución nacida en Italia en el siglo XVI, y no comenzó a extenderse por Europa hasta principios del XIX. En España, el primero, el actual Real Conservatorio Superior de Música de Madrid, fue fundado en 1830, y se abrió a los alumnos en enero de 1831. Algo después (1838) abrieron sus puertas

3. Giner también animó a su hermano Hermenegildo a escribir manuales de estética, y este respondió con Teoría del Arte e Historia de las Artes Bellas en la Antigüedad (1873), y un Manual de Estética y Teoría del Arte e Historia abreviada de las artes principales hasta el cristianismo (1894), obras semejantes entre sí y parecidas, asimismo, al Compendio de Estética traducido por Giner o las ideas presentadas por él en Estudios de literatura y arte. Parte de estos textos, sobre todo los de Hermenegildo, serían luego utilizados en la ILE. 
el de Barcelona y el del Teatro del Liceo (1847), en la misma ciudad; les siguen el de Valencia (1879), Oviedo (1887) y Sevilla (1888). A partir de la década de los 70 comienzan a inaugurarse más academias de música y formarse bandas de carácter civil pero, como se puede ver, todo sucedió durante el último cuarto del siglo (Gómez Amat, 1988: 259); y, en todo caso, el Real Conservatorio fue el único centro autorizado para emitir títulos oficiales de músico hasta 1905 (Sarget Ros, 2000: 127). Cuando se inauguró lo hizo con el nombre de Real Conservatorio de Música y Declamación de María Cristina, a cuyo patrocinio se debió, al menos en parte, su existencia. Era conocida la afición de la reina consorte por la música, y aunque de entrada la opinión pública recibió con alegría la apertura del Conservatorio, las críticas llegaron pronto. Como ya se ha dicho, el gusto desmesurado por lo italiano era entonces la característica más evidente y a la vez la mayor tara de la sociedad burguesa aficionada a la música en España ${ }^{4}$. La reina, napolitana de origen, había puesto al frente de la institución al cantante italiano Francesco Piermarini, cuyo programa consistía esencialmente en imitar el del conservatorio de Nápoles. Resulta natural, por ello, que fuera diana habitual de críticas y debates durante casi toda la centuria, cosa que propiciaron una sucesión de directores poco aptos o demasiado politizados y las magras ayudas que recibió de la Corona tras su aparatosa fundación.

Cuando Giner regresó a Madrid, el hombre al frente del Real era Emilio Arrieta (1823-1894), compositor — principalmente de ópera y zarzuelay antiguo profesor de composición de la misma casa. Tomó la dirección en 1868, y no la dejó hasta su muerte en el 94. Federico Sopeña dibuja un afilado retrato de su forma de operar:

Arrieta es un claro testimonio de una cierta «constante de adaptación» política en los directores del Conservatorio, desde Eslava hasta Bordas, con la muy digna y liberal excepción de Bretón. El caso de Arrieta es singular por el descaro y deja pálido aquello de «siempre con la situación» atribuido a Eslava. Protegidísimo por Isabel II, que construye para sus óperas un teatro en Palacio, le vemos en 1868 como autor de una marcha

4. Tomás Marco asevera que solamente el teatro lírico italiano o italianizante tuvo algún predicamento entre el público burgués durante el XIX, y si hubo intentos de cambiar este paradigma, chocaron contra «el baluarte de la indiferencia social impenetrable». Es más: «los raros compositores que atravesaron el muro del Teatro Real lo hicieron en circunstancias penosas y precarias y, muchas veces, al precio de traducir sus libretos al italiano» (Marco, 1989: 25). El célebre Tomás Bretón, afirma Marco, se vio obligado a presentar su ópera Los amantes de Teruel (1889) traducida al italiano y bajo el título de Gli amanti di Terolo (ibid.). 
titulada «Abajo los Borbones» [...]. Encarga muy pronto un buen retrato del Rey Amadeo y luego compone otra marcha con motivo del primer matrimonio de Alfonso XII, marcha que bien podría subtitularse «Arriba los Borbones». Navega siempre de la mano de su gran amigo Adelardo López de Ayala, con quien vive (Sopeña, 1990: 134).

Sopeña afirma, además, que Arrieta fue un claro partidario del decreto de Orovio, cosa que afecta a Giner tanto ética como personalmente. Don Francisco dejaba su postura rotundamente clara en un conocido artículo de 1878 llamado «Sobre la Institución y el Conservatorio», publicado en el diario El Pueblo Español, en el que criticaba duramente la gestión del director. Entre otras cosas, reprochaba a Arrieta que se hubiera centrado en inversiones superficiales, como la de arreglar un salón de conciertos, descuidando necesidades más acuciantes e incluso ordenadas por decreto real, como la creación de una cátedra de Estética y Literatura musical:

Acaso el Sr. Arrieta, desestimando el valor de esta clase de estudios, ¿podría creer que nada hay tan natural como el que un músico desconozca teórica y prácticamente la historia de su arte, la serie de sus grandes obras, el carácter y estilo de las diversas épocas, todo aquello que, por ejemplo, con tanta modestia y tan general aplauso, ha enseñado el Sr. Rodríguez, una de nuestras primeras ilustraciones, en la Institución Libre de Enseñanza? (OC, XV: 223).

Giner reivindica, como ya lo hiciera en Cádiz, la importancia de la estética y la teoría, y de ese equilibrio entre acción y conocimiento que se encuentra en la concepción artística de Krause. Incluso las voces más filorrománticas del momento, insiste el autor, «se afanan por reivindicar, no obstante, el valor de la reflexión y del estudio, para dar a ese fruto [la creación "pura"] suelo favorable en que pueda desarrollarse libremente» (225).

La primera parte del artículo comienza como una glosa al discurso de apertura del curso en la ILE, y es en realidad una queja explícita contra la política estatal en materia de educación. Giner habla del espíritu libre de la Institución, «al cual debe la historia intelectual del mundo sus grandes hechos y todos sus nombres ilustres», y que «no se cultiva en España hoy por hoy, para nuestra mengua, más que en un solo centro docente, en aquel donde el profesor es absolutamente libre en sus creencias y doctrinas» (220). Al colocar después de estas aseveraciones la crítica al Conservatorio, Giner estaba reforzando sus acusaciones contra Arrieta: este, como la ILE, sí tenía libertad y medios para mejorar las enseñanzas de su centro, y había elegido no hacerlo. Pero la Institución no es el único contraejemplo que propone Giner en el artículo: 
¿No siente, además, el Sr. Arrieta, que una institución privada, la Academia de Santa Cecilia en Cádiz, cuyo próspero estado (unos 700 alumnos) habrá podido pasar inadvertido al celo del Director de nuestro primer Instituto musical, se le haya anticipado desde hace tres o cuatro años a crear clases teóricas (Historia Universal, Acústica, Estética e Historia de la Música, e Historia general de las Bellas Artes), comprendiendo discretamente lo funesto de la general incultura de nuestros artistas — con cortísimas excepciones - y aspirando a remediarla por medios de tan pausado como seguro influjo?

Don Francisco, que aún consideraba que el centro matritense «más merecía el nombre de Conservatorio que el de Escuela» —en ese momento se llamaba solamente Escuela de Música y Declamación-, a causa de su inmovilismo, no olvidaba sus vínculos con Santa Cecilia, ni ocultaba el orgullo por el trabajo bien hecho.

Las demandas de Giner fueron escuchadas, pero no serían satisfechas hasta 1901, tras la muerte de Arrieta, el tránsito de dos directores fugaces y la toma de posesión del cargo por parte de Tomás Bretón, bajo cuyo liderazgo el Real comenzó a mejorar sensiblemente; célebre como operista y zarzuelista, fue uno de los más decididos a cambiar el estado de cosas en el Real. En 1894 hubo un intento serio de aplicación de las reformas propuestas por Giner, con Gabriel Rodríguez y el célebre Felipe Pedrell como adalides, pero la nueva dirección del Conservatorio - Jesús de Monasterio- y el cambio en el gobierno nacional —Cánovas subió al poder- retrasaron la reforma (Sánchez de Andrés, 2009: 248). Un nuevo cambio de gobierno, ahora con Sagasta al frente, la creación del Ministerio de Instrucción Pública y un clima general de aperturismo respecto a la innovación educativa permitieron el comienzo efectivo de una nueva etapa: Bretón fundó la cátedra de Historia y Filosofía de la Música y, además, hizo instalar la calefacción en el centro, que hasta entonces había carecido de ella.

\section{La música y la ILE}

Platón, en el libro III de la República ${ }^{5}$, es el primer pensador occidental en señalar de forma práctica y aplicada la importancia de la música en la

5. «Así los jóvenes, como si fueran habitantes de una región sana, extraerán provecho de todo, allí donde el flujo de las obras bellas excita sus ojos o sus oídos como una brisa fresca que trae salud desde lugares salubres, y desde la tierna infancia les conduce insensiblemente hacia la afinidad, la amistad y la armonía con la belleza racional [...]. La educación musical es de suma importancia a causa de que el ritmo y la armonía 
educación de los jóvenes, y lo cierto es que sus ideas cuadran, a grandes rasgos, con el discurso institucionista en el momento: desde los primeros estatutos de la ILE se implementa la presencia de la música en sus programas y, más concretamente, de la música enseñada de tal manera que su aprendizaje resulte orgánico, placentero, natural. Si Giner había denunciado la excesiva instrumentalización del aprendizaje musical en el Conservatorio, y su carencia de un arquitrabe teórico-estético que la soportara, el pecado de las enseñanzas generales de música hasta la fecha era, podríamos decir, el opuesto: un exceso de historia y teoría que no permitía al niño o al adolescente ejercitar sus capacidades musicales ni comprender de manera práctica el funcionamiento de aquello que le estaban explicando.

Hay acuerdo casi unánime en que los modos más naturales de aprendizaje musical son los que se basan en el ritmo corporal y en la voz, antes de prestar atención a los instrumentos; asimismo, las actividades en grupo resultan más estimulantes y promueven un desarrollo cognitivo más intenso que la práctica en solitario. En los programas de la ILE se contemplaban ambas cosas. Como sabemos, la Institución comenzó funcionando como una escuela de enseñanza superior, de un nivel parejo al de las universidades; más adelante veremos qué desarrollo tuvo lo musical en este periodo. En 1888, sin embargo, las enseñanzas primaria y secundaria acapararon mayor protagonismo en la Institución.

son lo que más penetra en el interior del alma y la afecta más vigorosamente, trayendo consigo la gracia, y crea gracia si la persona está debidamente educada, no si no lo está. Además, aquel que ha sido educado musicalmente como se debe es el que percibirá más agudamente las deficiencias y la falta de belleza, tanto en las obras de arte como en las naturales, ante las que su repugnancia estará justificada; alabará las cosas hermosas, regocijándose con ellas y, acogiéndolas en su alma, se nutrirá de ellas hasta convertirse en un hombre de bien. Por el contrario, reprobará las cosas feas - también justificadamente- y las odiará ya desde joven, antes de ser capaz de alcanzar la razón de las cosas; pero, al llegar a la razón, aquel que se haya educado del modo descrito le dará la bienvenida, reconociéndola como algo familiar» (República, III, 401c, d, e, y 402a). Después, Aristóteles y pensadores romanos como Cicerón o Quintiliano siguieron teniendo muy en cuenta la música en la formación de las personas y, especialmente, de los niños. Ya en el siglo X, Boecio volvió a insistir en la relevancia de la música para la configuración del espíritu, y se puede decir que desde entonces a finales del siglo XVIII es el ámbito eclesiástico el que acapara la tribuna de opinión en la materia. Si, por su parte, Platón adopta una actitud beligerante contra ciertas escalas y modos de canto o tañido, Giner, más moderado, no dejaría de criticar algunas de las músicas más nuevas, como la de Wagner, cuyos desarrollos cercanos a la atonalidad juzgaba demasiado ambiguos y confusos. 
Había dos formas complementarias en que los alumnos más jóvenes accedían a la educación musical. Por una parte, en las propias lecciones de música, que a veces impartió Giner en persona; por otra, y de modo transversal, en otras materias, de acuerdo con el sistema de aprendizaje continuo y circular favorecido por la Institución:

La ILE realizó una verdadera innovación educativa en nuestro país (siguiendo el antecedente del Colegio Internacional de Salmerón) al integrar la música como materia de la enseñanza general a todos los niveles, algo completamente novedoso en España. El hecho de que se incorporase así a los programas de enseñanza [...] y que nunca desapareciese de ellos, a pesar de las dificultades económicas de algunas etapas, demuestra que Francisco Giner y los institucionistas en conjunto consideraban la música como una materia fundamental que debía formar parte de la cultura general de cualquier hombre y de cualquier ciudadano español (Sánchez de Andrés, 2009: 256-257).

De acuerdo con estos principios de actuación, Giner de los Ríos incluía cuidadosamente referencias a la música en asignaturas como Lógica, Ética o, especialmente, Retórica y Poética — ha quedado registrado en su diario de clase y en los de sus alumnos-, por cuya integración en los programas educativos había abogado siempre. Con esta estrategia no solo se conseguía aumentar el caudal de enseñanzas musicales, un objetivo en sí mismo, sino, además, y esto es más importante, conectar sólidamente los diversos saberes. Así, de nuevo según Sánchez de Andrés, cuando terminaba de explicar los géneros literarios mayores, Giner dedicaba una lección completa a estudiar «la combinación de la poesía dramática con la música: Ópera-Zarzuela-Vaudeville-Tonadilla» (ibid.: 255). Igualmente, cuando trabajaba por las reformas en Santa Cecilia y el Real Conservatorio, Giner puso mucho énfasis en el estudio de la acústica desde el punto de vista más científico-físico, un hecho que también favorecía la cohesión entre materias educativas diversas.

Otro aspecto en que los institucionistas acertaron, como avanzábamos, fue el de insistir en la práctica de la música. Se había hecho desde los primeros tiempos de la ILE, cuando los alumnos eran de mayor edad: según Sopeña, don Francisco «tenía miedo de que apareciera la Institución sin que los que tocaran y cantaran fueran los alumnos. El conflicto estaba en no saber cantar la gente mayor y allí no había todavía niños» (1990: 139). A pesar de ello, afirma, «se cantó alrededor de un viejo armónium que había pertenecido a Don Fernando de Castro, al que se unieron las desafinaciones de aquellos señores que no habían cantado en su vida» (ibid.). 
Las actividades de conjunto coral fueron de gran importancia para que la ILE pudiera continuar con su fomento de la música. En un artículo sobre ciertas «escuelas industriales» norteamericanas —en Coloradoque proponía como modelo, el maestro describía la práctica coral en las mismas: «se reúnen para cantar, a veces, hasta varias clases, si bien en ocasiones se forma una Sección especial para atender a las necesidades del individuo o al cultivo de las aptitudes musicales que puedan tener algunos» (OC, XII: 139) ${ }^{6}$. Las actividades de canto coral, además, reforzaban el cariz igualitario de esta doctrina de enseñanza; en el mismo volumen escribía Giner:

Y no hablemos de cuanto hay que hacer en la esfera moral y en la afectiva, no menos importantes, aunque sí harto más desatendidas todavía ante el soberano despotismo del talento, que todo lo disculpa, a todo se atreve y lo puede todo. Porque si las deficiencias y lagunas de los estudios y la cultura intelectual piden remedio, no menos lo piden los vicios del sentimiento (ibid.: 82).

Es importante, además, el hecho de que todas las lecciones de Historia de la Música incluyeran audiciones que las ilustraran. Giner lo planteaba de un modo más sencillo: se trataba, simplemente, de educar a una generación en el aprendizaje activo, en el cultivo del pensamiento, «tan imperfecto en nuestra juventud, ya por desordenada sobrestima de la vivacidad y agilidad de entendimiento - uno de los mayores estímulos de perversión intelectual y moral-, ya por el hábito de la memoria mecánica y pasiva» (ibid.).

A pesar de su satisfacción por los avances en la ILE, don Francisco también había escrito, en el artículo sobre el Conservatorio: «es tan exiguo todavía el movimiento de nuestra cultura intelectual, que a nadie extrañará, probablemente, si tratamos aún de discursos e inauguraciones» (OC, XV: 217). Así, al tiempo que actuaba directamente sobre el sistema educativo, Giner logró prestar atención a otras formas más amplias de difusión de la cultura musical. Aprovechando el edificio de la propia ILE y,

6. También escribía, en el apartado sobre la música de Estudios de literatura y arte: «así, en la originaria poesía interior del ánimo, la Música de todo espíritu es polífona; consta de muchas voces: y de este modo el músico representa interiormente la vida estética mediante dos, tres, cuatro y muchas voces diferentes; sin lo cual, no podría componer sino música de una voz, y siempre de la misma voz. Interesa además esto para reconocer cuán natural y conforme a la esencia del pensamiento y del sentimiento es acompañar a una voz cantante con otras varias, y aun expresar un determinado sentimiento y estado de ánimo de un solo hombre por medio de dos, tres y más voces» (Giner, 1876: 88-89). 
más adelante, el del Ateneo de Madrid, comenzaron a celebrarse una serie de conciertos y conciertos-conferencia que dieron en llamarse «veladas musicales».

Entre 1876 y 1888, su etapa universitaria, en la ILE se celebraron muchas de estas reuniones. La asistencia de Giner era muy frecuente, y, junto con Gabriel Rodríguez, se ocupó de la organización de varias de ellas. La mayoría consistía en una suerte de conciertos didácticos o conciertos-conferencia, en los que se seleccionaba un programa determinado y se complementaba con una explicación histórico-teórica accesible al público general. De ahí, en parte, el éxito de estas veladas musicales frente al de otros ciclos de conferencias que se programaron: comenzaron a atraer gente ajena a la ILE —eran abiertas al público—, y se celebraran por la tarde o por la noche, en un horario que lo permitía. En cuanto al repertorio, sabemos que además de obras de Haydn, Mozart, Beethoven, Mendelssohn, Schumann y Chopin, hubo al menos una velada — sin duda fueron más- compuesta «toda de música española, ejecutándose el trío escrito expresamente por el maestro Chapí» (en la Crónica de la música, cit. por Sánchez de Andrés, 2009: 253); Sopeña, por su parte, menciona que se llegaron a interpretar fragmentos de Don Giovanni de Mozart, y, «uno de los días más felices del Giner músico», una reducción para piano de Las estaciones, «de su querido Haydn» (138) Giner aprovechó las veladas para promocionar la música de cámara y el lied, formas verdaderamente minoritarias por las que sentía especial cariño.

Después del 81, ya convertidas en una sólida institución, las veladas se trasladaron al Ateneo; Giner continuó asistiendo con frecuencia, casi siempre como espectador.

\section{Más allá de la ILE: la Residencia y las Misiones Pedagógicas}

Es difícil decir cuál de las empresas musicales de Giner tuvo, a la postre, mayor trascendencia, pero sin duda la vida musical de la Residencia de Estudiantes fue la más elevada, la más relacionada con el presente musical del momento, y quizá también la que más se acercó a los ideales krausistas acerca de la educación como parte integrada en la vida de los jóvenes. A pesar de que en ocasiones se exagere su esplendor, no cabe duda de que allí sucedieron grandes cosas, y el plano musical no fue una excepción; antes al contrario. Por la casa pasaron figuras extranjeras tan relevantes como Stravinski, Ravel o Poulenc, y lo mejor del panorama musical español: Óscar Esplá, Joaquín Turina y Manuel de Falla, el nombre más importante de la música nacional en el momento. Acogió conciertos, conferencias y 
reuniones musicales de todo tipo, se fundaron varios coros, y se integró todo ello con naturalidad en su vida cotidiana.

La Residencia se fundó en 1910, y desde este momento la dirigió, a petición de Giner de los Ríos, Alberto Jiménez Fraud, hasta su exilio forzoso en el 36. El ex secretario de la Junta impulsó la música en la vida de la Residencia de un modo admirable; al igual que Giner en Santa Cecilia o en las veladas de la ILE y el Ateneo, afirma Adela Presas que Fraud «no solo tenía la idea, sino la habilidad para involucrar en ella a aquellas personas que consideraba idóneas para llevarla a cabo» (2004: 65-66):

Y podemos ver cómo, pese a la intención formativa con que se plantearon las primeras sesiones y el coro de residentes, tanto la importancia de los músicos como la de los intérpretes que frecuentaban la casa, ya como residentes o como visitantes, hizo que poco a poco estos recogidos conciertos fueran adquiriendo un mayor relieve, que destacará ya nítidamente con la fundación de la Sociedad de Cursos y Conferencias y los importantes conciertos que esta patrocinó (ibid.).

Desde los primeros días de la Residencia en el n. ${ }^{\circ} 14$ de la calle Fortuny - contaba solo con diecisiete plazas-, refiere Presas, hubo un piano de media cola en el salón. Muy pronto el residente Antonio Juan Onievo, con ayuda de Eugenio d'Ors, organizó el coro en el que se cantaban canciones sencillas, esencialmente folclore; parte de ellas las armonizaría luego Martínez Torner en sus Cuarenta canciones españolas. Él mismo pasaría a dirigir el coro en 1916, aunque no está claro con qué asiduidad ensayaban o actuaban; pero el vínculo de Torner con el centro siempre fue intenso, como se evidencia en el prólogo: «el deseo de la Residencia [...] es que la lectura de sus páginas deje en el ánimo de nuestros jóvenes estudiantes un sedimento de belleza y un ansia creciente de conocimiento y amor hacia la tradición artística de nuestra patria» (1924: XV).

El músico asturiano aportó mucho a la Residencia. Compaginó con la colaboración sus labores de recopilador de folclore y su empleo en el Centro de Estudios Históricos, donde trabajó a las órdenes de Menéndez Pidal, que dirigía el Departamento de Filología. Además de la dirección del coro, Torner divulgó gran parte de su tarea en las conferencias que se celebraban asiduamente en la Residencia, en las que también participaron Menéndez Pidal, Bal y Gay y Adolfo Salazar, gran introductor de la música contemporánea en España (llegó a hablar de Schoenberg en alguna de sus charlas) ${ }^{7}$.

7. Salazar redactó muchos de los programas y guiones para los conciertos-conferencia; además, «procuraba aprovechar la visita de los músicos importantes como Ravel, Stravinski, 
Va quedando patente que en la Residencia, más allá de las iniciativas concretas, se iba generando y fortaleciendo un ambiente de aprendizaje y continuo disfrute de la música. Bal y Gay, en este sentido, decía preferir los conciertos nocturnos, y considerarlos mejores para los estudiantes, por su intimidad:

Quienes en ellos actuaban eran músicos de bien merecido prestigio, pero al mismo tiempo figuras familiares en la vida musical madrileña, de la que los residentes filarmónicos formábamos parte; así podíamos acercarnos a ellos y plantearles cuestiones musicales que nos interesaban, cosa que no habríamos osado hacer con un Ravel, un Falla o un Stravinski. Además de esos, el repertorio cultivado en aquellas sesiones íntimas estaba compuesto por la música clásica y romántica que necesitábamos como base de nuestra educación [...]. Reuniones posmeridianas, casi siempre dominicales, tenían lugar en el salón en torno al piano. Edward Wilson —que estaba traduciendo entonces las Soledades de Góngora y hoy es profesor de Español en la Universidad de Cambridge- leía conmigo a cuatro manos una gran cantidad de sinfonías y cuartetos clásicos que se guardaban en nuestra biblioteca; muchas veces, a petición de José Solís [...] me enfrentaba a Chopin; algunas tardes pasábamos de la música culta a la popular (en Pérez-Villanueva, 1990: 216).

Bal y Gay refiere, también, la presencia de Lorca y Alberti, quienes a su vez recogieron en escritos autobiográficos sus experiencias. Lorca, en particular, vivió durante largos periodos en la Residencia, y colaboró muy activamente en las conferencias: Presas Villalba habla de su «gran predilección por las canciones folklóricas, en las que mostraba lo más sabroso del pueblo». Tanto sus habituales improvisaciones en el piano del salón como sus conferencias-concierto generaban una «fascinación debida a la conjunción que en él se daba de lo culto y lo popular, arrastrando a sus compañeros a seguirle en sus viajes musicales por España». Lorca conocía los trabajos de Torner y Felipe Pedrell, pero imprimía un aire más bohemio y relajado a sus enseñanzas; memorable, según Presas, fue el concierto que ofreció junto a la cantante y bailarina La Argentinita en 1933; en 1935, cuando estos conciertos se habían trasladado a un nuevo auditorio

Poulenc, etc., para hacer un concierto en la Residencia, y si además incluía una conferencia, mejor. Se prestó atención a las diversas tendencias musicales de la época, desde la recuperación de repertorios preclásicos, hasta recitales folklóricos, o la música contemporánea, a la que se dedicaron cuatro importantes conciertos a partir de 1933, que serán una auténtica ventana abierta de novedades en el Madrid de los años treinta» (Presas, 2004: 88). 
externo, volvieron a tocar para los residentes (Presas, 2004: 74). Se recoge aun un último testimonio esclarecedor, extraído de la correspondencia de Juan Ramón Jiménez:

Por la noche, y a fin de que los alumnos, que pueden salir si quieren, no salgan, cosa difícil ya por la distancia que hay al centro, se organiza hasta las once un concierto de canto. Da gusto ver a tanto muchacho de 15 a 25 años, tan limpios, tan alegres, cantando y tocando cantos populares. Anoche, por ejemplo, no salió uno solo [...]. Además se dan conciertos todos los sábados» (2004: 69).

En conclusión: en la Residencia se logró un clima de respeto, cultura y vida intensamente artística que estaba muy cerca del ideal krausista de Giner y los demás; la presencia de la música y un enfoque lúdico-didáctico de la misma desde el principio contribuyeron en gran medida a estos logros. El crecimiento de la Residencia, tanto en tamaño como en prestigio, es parejo al crecimiento de su vida musical y al de un Madrid que iba despertando a la música de cámara, a las vanguardias europeas y a una forma diferente de escuchar y hacer música. A esto ayudó no poco que la Junta para la Ampliación de Estudios dispusiera de un fondo para que los jóvenes músicos pudieran estudiar fuera, de modo que, aparte de verdaderas avanzadas españolas en el extranjero - Falla en París—, se inició y se potenció un continuo ir y venir de influencias y novedades musicales entre las generaciones más jóvenes.

Todos estos procesos tuvieron lugar en centros de educación muy concretos, como la ILE, o en enclaves estrechamente relacionados con ellos, como la Residencia. Sin embargo, uno de los últimos esfuerzos que se hicieron antes de la guerra buscaba trascender la centralización urbana de la cultura y desplazarse a las periferias y las zonas rurales, donde el índice de analfabetismo todavía superaba el 40\%. Así, las Misiones Pedagógicas se pusieron en marcha en el 1931, bajo la dirección de Bartolomé Cossío y al amparo de la recién proclamada II República.

Tiempo atrás, en 1881, Giner de los Ríos y Cossío ya habían concebido esta idea de unas «misiones ambulantes», sin éxito en sus intentos de ponerlas en marcha; hubo alguna tentativa experimental, en la que estuvieron implicados Rafael Altamira o Cossío, pero el servicio propiamente dicho no se creó hasta el mismo año 31. La idea era sencilla: un grupo de maestros e intelectuales, remedando el modelo de las misiones eclesiásticas, se desplazaría a las zonas rurales con menor o nulo acceso a la cultura y trataría de despertar el interés del pueblo por la misma. Así, el Servicio de Bibliotecas se ocupó del fomento de la lectura, proporcionando 
bibliotecas fijas o itinerantes; la Sección de Cine y el Museo Ambulante buscarían realizar una tarea similar en sus terrenos, y el Retablo de Fantoches - títeres- y el Teatro del Pueblo otro tanto. La difusión de la música halló su lugar en esta iniciativa, desde luego, y el enlace más directo con la Residencia y el movimiento institucionista no sería otro que Martínez Torner, único director del Coro del Pueblo.

El Teatro y el Coro del Pueblo acostumbraban a viajar juntos, ya que, según Rodríguez Richart, sus componentes, unos cincuenta estudiantes de ambos sexos, eran los mismos (2009: 124). Sabemos que los implicados eran absolutamente voluntarios: «estudiantes universitarios en su mayoría, generosos e idealistas, que sacrificaban sus fines de semana y hasta parte de sus vacaciones de verano para participar en el teatro, en el coro o en otras actividades» (ibid.), chóferes que cubrían los trayectos sin cobrar y autobuses cuyo alquiler no se cobraba al Patronato, que no disponía de un presupuesto generoso. Además del Coro, en las Misiones también se puso en funcionamiento el Servicio de Música, que consistía básicamente en viajar con un gramófono y una pequeña selección de discos de pizarra, que durante un tiempo fue responsabilidad del alicantino Óscar Esplá8, mientras que Torner y Pablo de Andrés Cobos se encargaban de redactar pequeñas reseñas bibliográficas para los maestros encargados del Servicio. Los discos y el reproductor podían quedarse en los pueblos, o permanecer una corta temporada y ser luego llevados a otro lugar. Normalmente se dejaban en el colegio al cuidado de los maestros, quienes organizaban audiciones por la mañana para los niños, y por las tardes o noches para los adultos, a veces también dentro de la escuela. En cuanto al repertorio ofrecido, era de lo más variado:

Con el canto gregoriano y la lírica regional española se incluyen obras de Bach, Haendel, Mozart, Beethoven, Schubert, Mendelssohn, Weber, Chopin, Liszt, Wagner, Rossini, Berlioz, Gounod, Verdi, Franck, Brahms, Strauss, Saint-Saëns, Debussy, Mussorgsky, Borodín, Rimsky Korsakoff, Grieg, Puccini, Dukas, Ravel, Stravinski, Chapí, Bretón, Albéniz, Falla, Esplá, Turina, etc. La preferida es la zarzuela y la popular regional junto a algunas piezas sencillas de los clásicos (Canes Garrido, 1993: 156).

8. Nigel Dennis (2011: 23) comenta que en las casi performance en que consistían las sesiones del Museo del Pueblo también se ponía música clásica de fondo; «todo iba encaminado hacia el estímulo de la experiencia estética que tanta importancia tenía para Cossío». 
Qué hay tras el «etc.» de Canes no lo podemos saber, pero la lista ya parece suficiente. De esta manera, «ingenua pero eficaz», según Sopeña (144), la visión de Giner, Cossío y los demás iba tomando forma. Hasta finales de 1933 se repartieron treinta y ocho gramófonos, una cifra en realidad muy escueta, pero los municipios que el Teatro y el Coro visitaron fueron muchísimos más. Además, los maestros locales, a quienes se solía confiar el gramófono, acostumbraban a viajar a los pueblos cercanos para dejarlo prestado unos días. Era una forma precaria de acercar la música a la gente, pero era la primera y la única. Hacia el final de las misiones se habían entregado casi ochenta.

Sea como sea, y sabiendo que el presupuesto anual de 1934 para todas las Misiones, salvo el Servicio de Bibliotecas, fue de 650.000 pesetas ${ }^{9}$, comprendemos la verdadera importancia del voluntariado en esta iniciativa. María Luisa Mallo ofrece un detallado testimonio de la rutina del Coro:

Las vacaciones de Navidad, Carnaval, Semana Santa y final de curso se empleaban en giras de quince días que posibilitaran el llegar a pueblos más remotos [...], como [los de] la Alta Sanabria, los Valles del Tiétar y el Tormes, la Sierra de Béjar [...] para deleitar gratuitamente con comedias y canciones a los campesinos y serranos que, según el testimonio directo de Jesús Gallego, «oían embobados las bellezas de nuestros clásicos, pues en los pueblos precisamente donde no hay teatros, es donde con más entusiasmo se escuchan las representaciones teatrales [...] y todo esto era obra de Torner y de Casona, asturianos a $[\mathrm{m}]$ bos hasta los tuétanos, a quienes algún día se hará justicia, honrándoles como se merecen (Mallo, 1980: 70).

A pesar de su lugar central en el Coro, durante los últimos años de la República los cargos de Torner se multiplicaron, aunque siguió dirigiéndolo y coordinando el Servicio de Música hasta al menos 1936. En 1932 entra como profesor en el Conservatorio, en la cátedra de Prácticas del Folclore, y también en la ILE, y en 1934 pasaría a formar parte de la Junta de Música. Tengamos en cuenta, para terminar, que Torner no solo se encargaba de seleccionar los materiales del coro y dirigirlo en las Misiones: también debía ensayar regularmente con los integrantes en Madrid, en la Escuela Normal del Paseo de la Castellana. Mallo habla de una labor verdaderamente «ingrata», "pues muchos de los estudiantes que componían los coros no tenían apenas conocimientos de solfeo» (Mallo, 1980:

9. En los años anteriores, desde 1931, los presupuestos habían sido de 300.000, 525.000 y 700.000 pesetas, respectivamente (Canes, 1993: 155). 
73). Como Torner siempre quiso que la música antigua española estuviera presente, tenía que realizar verdaderos esfuerzos para montar las obras de hasta seis voces de Tomás Luis de Victoria, Juan del Enzina o Antonio de Cabezón; toda esta febril actividad recuerda mucho el modo gineriano de desenvolverse. Torner, además, aún pudo sacar otro provecho para su propia actividad investigadora: «insisto en que la mejor música iba en dos direcciones: la que se escogía durante las excursiones, la que luego identificaba Torner y la que se incorporaba al teatro» (Sopeña, 1990: 144).

Dadas las limitaciones mencionadas, es evidente que tanto el Servicio de Música como el Coro del pueblo podían sentirse más satisfechos por la tarea que estaban realizando que por los resultados obtenidos, en términos absolutos. En episodios como el de la Misión de Sanabria, que relata Canes, en el que los maestros llegaron a una zona absolutamente miserable, con la población desnutrida y enferma (Canes Garrido, 1993: 160 ss.), quedaba claro que la nación estaba aquejada de problemas más graves que la incultura o el analfabetismo. Ello no restaba sentido a los esfuerzos de gentes como Torner o Casona, pero los dotaba de un matiz distinto, una realidad que quedó patente cuando se agudizó el clima prebélico, e incluso después del estallido de la guerra: entonces entidades como las Misiones o la Residencia devinieron símbolos, más allá de sus modestas actividades: eran vistas a la vez como dignos ejemplos de lo que los sublevados pretendían destruir, y como baluartes de resistencia frente a la barbarie. Un ejemplo: en el número 453 (19 de noviembre de 1936) del magacín gráfico Estampa, reconvertido en publicación de propaganda republicana tras el golpe, aparece un reportaje patriótico de Eduardo de Ontañón llamado «Las misiones pedagógicas, consuelo de heridos de guerra» (pp. 11-13). En él se narra, acompañada de muchas imágenes, una función del Teatro y Coro en un hospital de heridos del frente, donde el entusiasmo y la camaradería embargan a asistentes, voluntarios y profesores. Cuando el coro comienza a cantar jotas, tonadas y otras piezas regionales «al final, todos aplauden con igual contento, porque la voz popular les ha llegado por igual y les ha hecho despertar la dulce añoranza del paisaje nato que todos llevamos dormido dentro» (13).

El fin de todas estas iniciativas estaba ya cerca. Tras la sublevación de julio, Torner siguió trabajando en su investigación, y lo hizo, con pequeñas interrupciones, hasta que pasó a Francia en 1939, tras la caída del frente de Tarragona. Las interrupciones consistieron sobre todo en traslados: el asturiano y su familia se fueron desplazando con el Gobierno de la nación, según las sucesivas derrotas obligaban a este a cambiar de 
sede. Así, Torner marchó a Valencia ese mismo verano, en un coche del Ministerio de Instrucción Pública, llevándose buena parte de su archivo personal, y luego a Barcelona en octubre del 37, dejando esta vez gran parte del archivo tras de sí. En ambas ciudades continuó trabajando y publicando (González Cobas, 2002: 164 ss.). Las primeras semanas en Francia fueron verdaderamente traumáticas, y acabaron con Torner hospitalizado, enfermo de disentería, cerca del campo de refugiados de Argelés, de donde el Comité Inglés de Ayuda a los Refugiados Españoles lo había sacado. Su hijo mayor, Eduardo, había sido enviado a un lejano pueblo de Normandía.

Torner pasó el resto de su vida en Londres, donde mucho más adelante (1947) su familia se reunió con él. Según González Cobas, aunque fue muy bien considerado, «sin duda de ninguna clase, Torner nunca fue feliz aquí» (2002: 167). Trabajó para la BBC, dio conferencias, clases, musicó radiodifusiones de obras de Lorca, y en general continuó avanzando en el campo del folclore y la música tradicional española, publicando numerosas obras de diversa envergadura. Nunca regresó a España. Ampliamente reconocido, pero pobre, hubo de contar a menudo con la ayuda de otros exiliados mejor situados, y murió en 1955, en un hospital de beneficencia. La última actuación del Teatro y Coro del Pueblo había tenido lugar casi veinte años atrás, en julio del 36, en el madrileño Hospital de Sangre Giner de los Ríos.

\section{Coda}

En el fondo, en todos los campos en que tuvo alguna influencia, esta reforma heterogénea musical siguió una estrategia muy similar: ampliar las estructuras de conocimiento y difusión musical más allá de sus límites establecidos. En el Conservatorio, donde la música se enseñaba cada vez más como un arte mecánico, la reforma consistió en proveer a los músicos de la base estética e histórica que les era escamoteada. En las enseñanzas primarias y secundarias se introdujo la música transversalmente en casi todas las otras asignaturas, y también en la vida de la comunidad educativa en general, a través del coro y las veladas. Otro coro, el de la Residencia, sirvió para estrechar lazos entre los internos, mientras que la variedad $\mathrm{y}$ el atractivo de sus sesiones musicales permitieron que los alumnos «que pueden salir, si quieren, no salgan», como se congratulaba Juan Ramón. Mediante la música - y otras actividades-, un pequeño albergue de estudiantes de las afueras acabó siendo uno de los centros culturales más atractivos de la Edad de Plata. En cuanto a las Misiones, sencillamente 
llevaron la música allá donde apenas la había, y por mediación de Torner y otros revalorizaron tradiciones que se iban perdiendo en las periferias del país y de la cultura dominante.

Ya se ha insistido en el carácter colectivo de cada una de estas iniciativas, pero es indiscutible que, en última instancia, todas son producto de aquel andar resuelto y enérgico que comenzaron Giner de los Ríos y los suyos en los años 60 del siglo XIX. Resulta inevitable, desde nuestra posición actual, cuestionarse el estado de cosas en lo tocante a la pedagogía y la cultura musicales, y visualizar estos ciento cincuenta años como una progresión lineal. Las variables son numerosísimas, las circunstancias socioeconómicas muy diferentes, y es cierto que a menudo un velo arcádico suele distorsionar nuestra visión del periodo que se dio en llamar Edad de Plata. Pero, con todo, probablemente parte de lo que quiso hacer Giner en materia de música debería por fin ser realizado, y parte de lo que logró hacer, repetido.

\section{Bibliografía citada}

CANES GARRIDO, Francisco, «Las Misiones Pedagógicas: educación y tiempo libre en la Segunda República», Revista Complutense de Educación, 4, 1 (1993), pp. 147-168.

DenNis, Nigel, «Ramón Gaya y el Museo del Pueblo de la Misiones Pedagógicas», Escritura e Imagen, 7 (2011), pp. 15-26.

Estampa. Revista Gráfica y Literaria de la Actualidad Española y Mundial [Madrid], 453 (1936).

GINER DE LOS Ríos, Francisco, Estudios de literatura y arte, Madrid, Librería de Victoriano Suárez, 1876.

- Obras completas, VII: Estudios sobre educación, Madrid, Espasa-Calpe, 1935.

- Obras completas, XV: Estudios sobre las artes industriales y Cartas literarias, Madrid, Espasa-Calpe, 1926.

- Obras completas, XVI: Ensayos menores sobre educación y enseñanza, Madrid, Espasa-Calpe, 1927.

Gómez Amat, Carlos, Historia de la música española. 5. Siglo XIX, Madrid, Alianza, 1988.

GONZÁlez COBAS, Modesto, «El discreto exilio del musicólogo Eduardo Martínez Torner», en A. Fernández Insuela (ed.), Sesenta años después: el exilio literario asturiano de 1939 (Actas del Congreso Internacional celebrado en la Universidad de Oviedo), Oviedo, Universidad de Oviedo, 2000; <http://www.cervantesvirtual.com/nd/ark:/59851/bmcqz276> [consulta: 10 julio 2015]. 
KRAUSE, Karl Christian Friedrich, Compendio de Estética, traducido del alemán y anotado por Francisco Giner, Sevilla, Imprenta Girondés y Orduña, 1874; 2. edición ampliada con la Teoría de la música, Madrid, Librería de V. Suárez, 1883.

- Compendio de Estética, traducido del alemán y anotado por Francisco Giner, ed. Pedro Aullón de Haro, Madrid, Vérbum, 2009.

MALlo DEl CAMPO, María Luisa, Torner. Más allá del folklore, Oviedo, Universidad de Oviedo, 1980.

MARCO, Tomás, Historia de la música española. 6. Siglo XX, Madrid, Alianza, 1989.

MARTín Moreno, Antonio, «La enseñanza musical en España en el siglo XIX: el Curso completo de música de la Escuela Normal de Zaragoza (1861) y la Historia de la música de la Academia Santa Cecilia de Cádiz (1883)», Publicaciones. Facultad de Educación y Humanidades de Melilla, 35 (2005), pp. 75-108; <http://revistaseug.ugr.es/index.php/publicaciones/article/view/2293/2411> [consulta: 10 julio 2015].

MARTínez TORnER, Eduardo, Cuarenta canciones españolas, Madrid, Publicaciones de la Residencia de Estudiantes, 1924.

Ossa Martínez, Marco Antonio de la, La música en la guerra civil española, Cuenca, Universidad de Castilla-La Mancha, 2011.

PÉreZ-VillanueVa Tovar, Isabel, La Residencia de Estudiantes, Madrid, Ministerio de Educación y Ciencia, 1990.

Platón, República, ed. Conrado Eggers Lan, Madrid, Gredos, 2007.

Pliego DE ANDRÉS, Víctor, «El Servicio de Música: Eduardo Martínez Torner y Pablo de Andrés Cobos», catálogo de la exposición Las Misiones Pedagógicas, 1931-1936, Madrid, Sociedad Estatal de Conmemoraciones Culturales y Residencia de Estudiantes, 2006, pp. 414-443.

Presas Villalba, Adela, «La Residencia de Estudiantes (1910-1936): actividades musicales», Música. Revista del RCSMM, 10-11 (2003-2004), Madrid, Real Conservatorio de Música de Madrid, 2004, pp. 55-103.

RODRÍGUEZ RICHART, José, Dos patrias en el corazón. Estudios sobre literatura española en el exilio, Madrid, Vérbum, 2009.

SÁNCHEZ DE ANDRÉS, Leticia, «El pensamiento y la actividad musical de Francisco Giner de los Ríos. Iniciativas krausoinstitucionistas en el ámbito de la educación musical (1869-1915)», en José Manuel Vázquez Romero (ed.), Francisco Giner de los Ríos: actualidad de un pensador krausista, Madrid, Marcial Pons, 2009, pp. 199-258.

- «Manuales de origen krausista para la enseñanza de la estética y la historia del arte y de la música en los institutos de bachillerato», Revista Arbor. Ciencia, Pensamiento y Cultura, 187-749 (2011), pp. 535-545; <http://arbor.revistas. csic.es/index.php/arbor/article/viewFile/1324/1333> [consulta: 10 julio 2015]. 
SARGET ROS, M. ${ }^{a}$ Ángeles, «Perspectiva histórica de la educación musical», Ensayos: Revista de la Facultad de Educación de Albacete, 15 (2000), pp. $117-130$.

SOPEÑa IbáÑEZ, Federico, «La Institución Libre de Enseñanza y la música», Música. Revista del RCSMM, 1 (1994), pp. 125-146.

Fecha de recepción: 13-8-2015

Fecha de aceptación: 4-12-2015 